\title{
Causas de Variação da Produção de Leite em um Rebanho da Raça Holandesa em São Carlos, SP
}

\author{
Pedro Franklin Barbosa ${ }^{1}$, Geraldo Maria da Cruz ${ }^{1}$, José Ladeira da Costa ${ }^{2}$, Armando de \\ Andrade Rodrigues ${ }^{1}$
}

\begin{abstract}
RESUMO - O objetivo deste trabalho foi avaliar a importância dos efeitos de ano de parto (AP), estação de parto (EP), grupo genético (GG), sexo do bezerro (SB), causa de secagem (CS), idade da vaca ao parto (IP, em meses) e duração do período de lactação (DL, em dias) e de touro (PAI), na produção de leite (PL), em um rebanho da raça Holandesa. Um total de 684 observações, provenientes de 267 vacas criadas em um modelo físico de sistema de produção de leite mantido na Embrapa - Centro de Pesquisa de Pecuária do Sudeste, São Carlos, SP foi incluído nas análises. Os dados foram coletados no período de outubro de 1984 a dezembro de 1993 e analisados pelo método dos quadrados mínimos por meio de um modelo incluindo os efeitos fixos de AP, EP, GG, SB e CS, os efeitos linear e quadrático de IP e DL como covariáveis e o efeito aleatório de PAI. Houve efeitos de AP, EP, CS, IP (linear e quadrático), DL (linear e quadrático) e PAI sobre a PL. As variáveis GG e SB não influenciaram a PL. No período estudado, houve aumento linear da PL de 347,6 $\pm 22,02 \mathrm{~kg}$ de leite/lactação·ano. As vacas com lactações iniciadas no verão (janeiro-março) foram menos produtivas ( $4.325 \pm 82 \mathrm{~kg}$ ) que as com lactações iniciadas nas demais estações do ano $(4795 \pm 49 \mathrm{~kg})$. As vacas com lactações encerradas por motivo de pré-parto apresentaram maior PL $(4903 \pm 78 \mathrm{~kg})$ que as com lactações encerradas por baixa produção/outras causas (4452 $\pm 61 \mathrm{~kg})$. A PL foi influenciada pelos efeitos linear $(18,86 \pm 2,39 \mathrm{~kg} / \mathrm{mês})$ e quadrático $\left(-0,2934 \pm 0,0456 \mathrm{~kg} / \mathrm{mês}^{2}\right)$ da idade da vaca ao parto. Houve efeitos linear $(15,83 \pm 0,41 \mathrm{~kg} / \mathrm{dia})$ e quadrático $\left(-0,0057 \pm 0,0023 \mathrm{~kg} / \mathrm{dia}^{2}\right)$ da duração do período de lactação sobre a PL.
\end{abstract}

Palavras-chave: bovinos de leite, causa de secagem, fatores ambientais, efeitos genéticos, gado Holandês

\section{Sources of Variation on Milk Yield of a Holstein Breed Herd in São Carlos, SP}

ABSTRACT - The objective of this work was to evaluate the effects of year of calving (YC), season of calving (SC), genetic group (GG), calf sex (SEX), reason for drying-off (RD), cow age at calving (AGE, in months), lactation length (LL, in days) and sire (SIRE) on milk yield (MY) in a Holstein breed herd. A total of 684 observations, from 267 cows raised in a physical models of dairy cattle production system maintained at Embrapa - Centro de Pesquisa de Pecuária do Sudeste, São Carlos, SP, was included in the analysis. Data on milk yield were collected from October 1984 to December 1993 and analyzed by the least-squares method through a mathematical model including the fixed effects of YC, SC, GG, SEX and RD, linear and quadratic effects of AGE and LL as covariates and the random effect of SIRE. There were effects of YC, SC, RD, AGE (linear and quadratic), LL (linear and quadratic) and SIRE on MY. GG and SEX did not influence MY. In the studied period, there was a linear increase of MY in $347.6 \pm 22.02 \mathrm{~kg} / \mathrm{lactation}$.year. The cows freshening in the summer (January-March) were less productive (MY $=4,325 \pm 82 \mathrm{~kg}$ ) than those freshening in the other seasons of the year $(4,795 \pm 49 \mathrm{~kg})$. The cows with lactations terminated because of pre-calving presented higher MY $(4,903 \pm 78 \mathrm{~kg})$ than those with lactations terminated because of low production/other reasons $(4,452 \pm 61 \mathrm{~kg})$. The MY was influenced by linear (18.86 \pm 2.39 $\mathrm{kg} / \mathrm{mo}$.) and quadratic $\left(-0.2934 \pm 0.0456 \mathrm{~kg} / \mathrm{mo}^{2}\right)$ effects of AGE. There were linear $(15.83 \pm 0.41 \mathrm{~kg} / \mathrm{day})$ and quadratic $(-0.0057 \pm 0.0023$ $\mathrm{kg} / \mathrm{day}^{2}$ ) effects of lactation length on MY.

Key Words: dairy cattle, environmental factors, genetic effects, Holstein cattle, reason for drying-off

\section{Introdução}

A avaliação de causas de variação da produção de leite é importante para a escolha estratégica dos recursos genéticos, para o delineamento de programas de melhoramento genético e, também, para a recomendação de práticas de manejo adequadas aos diferentes sistemas de produção existentes no Brasil. A multiplicação de estudos, visando ao maior conhecimento e à melhor compreensão dos efeitos de fatores ambientais e genéticos na produção de leite, é necessidade reconhecida já há algum tempo (NAUFEL, 1965/ 1966; NEIVA et al., 1979; e FREITAS et al., 1983).

Em rebanhos da raça Holandesa, criados na

\footnotetext{
1 Pesquisador, Embrapa - Centro de Pesquisa de Pecuária do Sudeste, Caixa Postal 339 - 13560-970 - São Carlos, SP. E-mail: pedro@cppse.embrapa.br

${ }_{2}$ Pesquisador, Embrapa - Centro Nacional de Pesquisa de Gado de Leite, Rua Eugênio do Nascimento, 610 - Bairro Dom Bosco - $36038-330$ - Juiz de Fora, MG.
} 
região Sudeste do Brasil, vários fatores ambientais e genéticos foram identificados como importantes causas de variação da produção de leite, destacando-se o ano de parto, a estação de parto, a idade da vaca ao parto, o grupo genético, a duração do período de lactação e o touro (pai da vaca). Outros fatores, como o sexo do bezerro, a origem do reprodutor, a variedade de pelagem e a causa de encerramento da lactação, também têm sido estudados, mas com freqüência muito menor que os fatores destacados anteriormente.

$\mathrm{Na}$ raça Holandesa, o efeito do ano de parto foi relatado como importante causa de variação da produção de leite (NAUFEL, 1965/66; NEIVA et al., 1979; COSTA et al., 1982; QUEIROZ et al., 1987; REIS e SILVA, 1987; e BARBOSA et al., 1997). Os resultados obtidos são variáveis, observando-se desde aumentos crescentes até reduções significativas da produção de leite, no decorrer dos anos, com alguns casos de manutenção das médias.

A estação do ano em que ocorre o parto também influencia a produção de leite. Na região Sudeste, vários trabalhos têm mostrado que as maiores produções de leite são observadas quando as parições ocorrem no outono (abril-junho) e inverno (julhosetembro), como relatado por NAUFEL (1965/66), COSTA et al. (1982), FREITAS et al. (1983), QUEIROZ et al. (1987), REIS e SILVA (1987) e CONCEIÇÃO JR. et al. (1993). No entanto, BARBOSA et al. (1997) não encontraram efeito significativo da estação de parto sobre a produção de leite em um rebanho da raça Holandesa criado na região da Mantiqueira Paulista.

De acordo com ALVES NETTO et al. (1967), QUEIROZ et al. (1987) e REIS e SILVA (1987), o grupo genético da vaca tem influência na produção de leite, observando-se que as vacas do grupo genético denominado Gado Holando Brasileiro (GHB) e as puras de origem (PO) são mais produtivas que as vacas puras por cruza (PC) e cruzadas. No entanto, NEIVA et al. (1979), MADALENA et al. (1983), CONCEIÇÃO JR. et al. (1993) e BARBOSA et al. (1997) não verificaram diferenças significativas entre grupos genéticos na raça Holandesa. A avaliação dos efeitos deste fator é importante para a escolha estratégica dos recursos genéticos.

No Brasil, SIQUEIRA (1979) concluiu que as lactações seguintes ao nascimento de machos foram mais produtivas, entretanto, FREITAS et al. (1983) e BARBOSA et al. (1997) não encontraram diferenças significativas entre as lactações com relação ao sexo do bezerro.
A produção de leite varia com a idade da vaca ao parto, aumentando desde a primeira lactação até que a vaca atinja o seu completo desenvolvimento corporal e a maturidade fisiológica, mantendo-se elevada por alguns anos para, depois, decrescer, na medida em que o animal envelhece. No Brasil, vários pesquisadores verificaram efeito significativo, na forma quadrática, da idade da vaca ao parto sobre a produção de leite em rebanhos da raça Holandesa (COSTA et al., 1982; FREITAS et al., 1983). A estimativa de idade de máxima produção foi de 87 meses, correspondendo à quinta lactação (COSTA et al., 1982).

A duração do período de lactação está diretamente relacionada à quantidade total de leite e é responsável por grande parte da variação nesta característica. Efeitos lineares significativos da duração do período de lactação sobre a produção de leite, em rebanhos da raça Holandesa criados na região Sudeste do Brasil, foram relatados por NEIVA et al. (1979) e FREITAS et al. (1983).

A causa de encerramento da lactação não tem sido estudada com maior frequiência, porque geralmente não se dispõe deste tipo de informação. BARBOSA et al. (1997), analisando dados de produção de leite provenientes de um rebanho da raça Holandesa, encontraram efeito significativo da causa de encerramento da lactação, com as vacas cujas lactações foram terminadas por motivo de pré-parto, sendo mais produtivas que as com lactações encerradas por baixa produção ou outras causas.

O objetivo deste trabalho foi avaliar a importância dos efeitos de fatores ambientais e genéticos na produção de leite de um rebanho da raça Holandesa, mantido em um modelo físico de sistema de produção de leite na Embrapa - Centro de Pesquisa de Pecuária do Sudeste, São Carlos, SP.

\section{Material e Métodos}

Os dados $(\mathrm{N}=684)$ de produção de leite nas lactações (PL) de 267 vacas, filhas de 76 touros, foram observados no período de outubro de 1984 a dezembro de 1993, em um rebanho com predominância de animais puros por cruza (PC) da raça Holandesa Preta e Branca, mantido em um modelo físico de sistema de produção de leite na Embrapa - Centro de Pesquisa de Pecuária do Sudeste, São Carlos, SP.

O modelo físico de sistema de produção de leite encontra-se instalado em uma área de 96 hectares, em latossolo vermelho amarelo distrófico, de textura média (25 a 30\% de argila), baixa fertilidade natural 
976 Rev. bras. zootec.

e relevo suavemente ondulado (4 a 10\%). O clima é do tipo tropical de altitude, com temperatura média anual de $21,2^{\circ} \mathrm{C}$ (variando de 17,3 a $23,6^{\circ} \mathrm{C}$ ) e umidade relativa variando de 62 a $81 \%$ (média anual de $75 \%$ ). A média anual de precipitação pluvial no período foi de $1354 \mathrm{~mm}$, com evapotranspiração potencial média diária de $4,2 \mathrm{~mm}$, o que corresponde a um déficit hídrico de $344 \mathrm{~mm} /$ ano. Os ventos predominantes no modelo físico de sistema de produção de leite são o nordeste (30\%), o sudeste $(19,4 \%)$, o leste $(14,8 \%)$ e o norte $(12,3 \%)$, com velocidades variando de 3,1 a 4 metros por segundo.

As vacas em lactação foram mantidas em regime de pastagens de Andropogon gayanus (capim andropogon), Brachiaria decumbens (braquiária), Panicum maximum (capim tobiatã) e Pennisetum purpureum Schum. (capim-elefante) durante o ano todo, com suplementação alimentar constituída de volumosos (silagem de milho ou sorgo e capim elefante picado), dependendo da época do ano, e de concentrados, de acordo com a produção individual de leite, durante o ano todo, e ordenhadas mecanicamente, duas vezes ao dia, sem bezerro ao pé. As fêmeas em reprodução foram acasaladas com touros da raça Holandesa, por meio de inseminação artificial e monta natural (quando necessário), durante o ano todo.

O perfil tecnológico do modelo físico de sistema de produção de leite, adotado como referência para o fornecimento dos coeficientes técnicos, para a planilha de leite tipo B do Estado de São Paulo, foi descrito de maneira detalhada pela CÂMARA SETORIAL DE LEITE (1991), na qual podem ser obtidas informações adicionais.

A produção individual de leite foi controlada quinzenalmente. A produção de leite na lactação (PL) foi calculada utilizando-se as Normas Técnicas do Regulamento do Serviço de Controle Leiteiro (Portaria SNAP nº 45, de 10/10/1986, do Ministério da Agricultura e Abastecimento), publicadas pela Associação Brasileira dos Criadores de Bovinos da Raça Holandesa (ABCBRH, 1986). A fórmula usada para calcular PL foi a seguinte:

$\mathrm{PL}=\left(\mathrm{C}_{1} * \mathrm{E}_{1}\right)+\sum_{\mathrm{i}=2}^{\mathrm{n}}\left(\left(\left(\mathrm{C}_{\mathrm{i}}+\mathrm{C}_{\mathrm{i}-1}\right) / 2\right) * \mathrm{E}_{\mathrm{i}}\right)+\left(\mathrm{C}_{\mathrm{n}} * \mathrm{E}_{\mathrm{n}}\right)$,

em que

$\mathrm{PL}=$ produção de leite na lactação, em $\mathrm{kg}$;

$\mathrm{C}_{1}=$ quantidade de leite no primeiro controle, em kg;

$\mathrm{E}_{1}=$ intervalo entre o parto e o primeiro controle, em dias;

$\mathrm{n}$ = número de controles;
$\mathrm{C}_{\mathrm{i}}=$ quantidade de leite em cada controle $(\mathrm{i}=2$, $3,4, \ldots, \mathrm{n})$, em kg;

$\mathrm{E}_{\mathrm{i}}=$ intervalo entre dois controles consecutivos, em dias;

$\mathrm{C}_{\mathrm{n}}$ = quantidade de leite no último controle, em $\mathrm{kg}$; e

$\mathrm{E}_{\mathrm{n}}=$ intervalo entre o último controle e o encerramento da lactação, em dias.

Os dados foram analisados pelo método dos quadrados mínimos, por meio de um modelo matemático que incluiu os efeitos fixos de ano de parto (AP; 1984 a 1992), estação de parto (EP; verão = janeiromarço; outono = abril-junho; inverno = julho-setembro; e primavera = outubro-dezembro), grupo genético $(\mathrm{GG}$; cruzadas $=$ de 5/8 até $15 / 16$ Holandês, $\mathrm{PC}=$ puras por cruza, $\mathrm{GC} 1=\mathrm{PC}$ de primeira geração controlada, e $\geq \mathrm{GC} 2+\mathrm{PO}=\mathrm{PC}$ de duas ou mais gerações controladas + puras de origem), sexo do bezerro (SB; macho, fêmea), causa de secagem (CS; pré-parto, baixa produção/outras), efeitos linear e quadrático da idade da vaca ao parto (IP, em meses) e da duração do período de lactação (DL, em dias), e efeitos aleatórios de touro (PAI) e erro.

As vacas cruzadas tinham, além do Holandês, de 1/16 a 3/8 de genes oriundos de raças zebuínas, principalmente Gir e Guzerá. A distribuição dos grupos genéticos (GG), de acordo com os demais efeitos fixos, foi desigual, pois o número de observações variou de 2 a 60 para AP, 18 a 55 para EP, 62 a 124 para SB e 42 a 145 para CS. As interações de primeira ordem envolvendo GG e os demais efeitos fixos incluídos no modelo matemático foram testadas em uma análise preliminar dos dados, mas não foram significativas. Alguns touros foram utilizados ao longo de todo o período estudado, por meio de inseminação artificial, o que permitiu a conexão dos touros por meio dos anos de parto e dos grupos genéticos.

Todas as lactações foram incluídas no arquivo de dados, exceto aquelas terminadas por motivo de morte da vaca após o parto, antes de completar pelo menos três controles quinzenais (foram eliminadas cinco lactações por este motivo). As análises estatísticas foram feitas empregando-se os procedimentos disponíveis no "Statistical Analysis System" (SAS, 1993).

\section{Resultados e Discussão}

A média da produção de leite do rebanho no período estudado foi de $4957 \pm 31 \mathrm{~kg}$ em lactações de $305,5 \pm 3,4$ dias de duração. O coeficiente de variação foi igual a 16,22\%. A média observada neste trabalho foi superior à calculada para a região Sudeste 
$(3969 \pm 248 \mathrm{~kg})$, com base em 10 estimativas relatadas na literatura (NAUFEL, 1965/66; ALVES NETO et al., 1967; NEIVA et al., 1979; SIQUEIRA, 1979; COSTA et al., 1982; FREITAS et al., 1983; MADALENA et al., 1983; QUEIROZ et al., 1987; REIS e SILVA, 1987; e BARBOSA et al., 1997). Nos trabalhos revisados, há diferenças tanto nas condições de ambiente em que os animais foram criados, quanto na composição genética dos rebanhos e nas práticas de manejo adotadas. A média obtida neste trabalho reflete o potencial genético dos animais, as condições ambientais e as práticas de manejo adotadas no rebanho, colocando-o, em termos comparativos, bem acima da média dos rebanhos mantidos na região Sudeste.

O resumo da análise de variância da produção de leite é apresentado na Tabela 1 . Houve efeito significativo $(\mathrm{P}<0,05)$ de AP, EP, CS, IP (linear e quadrático), DL (linear e quadrático) e PAI, mas não de GG e SB na produção de leite.

$\mathrm{Na}$ literatura brasileira, em rebanhos da raça Holandesa criados na região Sudeste, o ano de parto tem sido relatado como importante causa de variação da produção de leite em quase todos os trabalhos. A maioria dos resultados obtidos no Brasil mostra que o ano de parto é importante na variação da produção de leite, como foi verificado no presente trabalho.

As médias estimadas por quadrados mínimos, de acordo com o ano de parto (Tabela 2), mostram que houve melhoria no desempenho do rebanho com a evolução dos anos de parto. A análise de regressão linear das médias nos anos de parto mostrou que a produção de leite aumentou 347,6 $\pm 22,02 \mathrm{~kg} / \mathrm{lactação.}$ Este resultado é superior ao obtido por QUEIROZ et al. (1987), em um rebanho com alto nível de manejo na região de São Carlos, que encontraram coeficiente de regressão linear da produção de leite nos anos de parto de $153,1 \mathrm{~kg}$. O aumento do desempenho no período estudado (1984 a 1992) é reflexo da mudança na composição genética do rebanho, por meio da utilização de touros provados e introdução de bezerras e novilhas de melhor potencial genético no rebanho em 1988, que começaram a produzir somente a partir do final de 1990, e das práticas de manejo adotadas, particularmente quanto à alimentação na época de escassez de pastagens (abril-setembro), com efeitos positivos sobre a produção. Os menores aumentos relativos observados no período de 1989 a 1991 (Tabela 2), provavelmente, foram causados pelo aumento do número de vacas jovens no rebanho e pela redução do número de descartes naquele período.

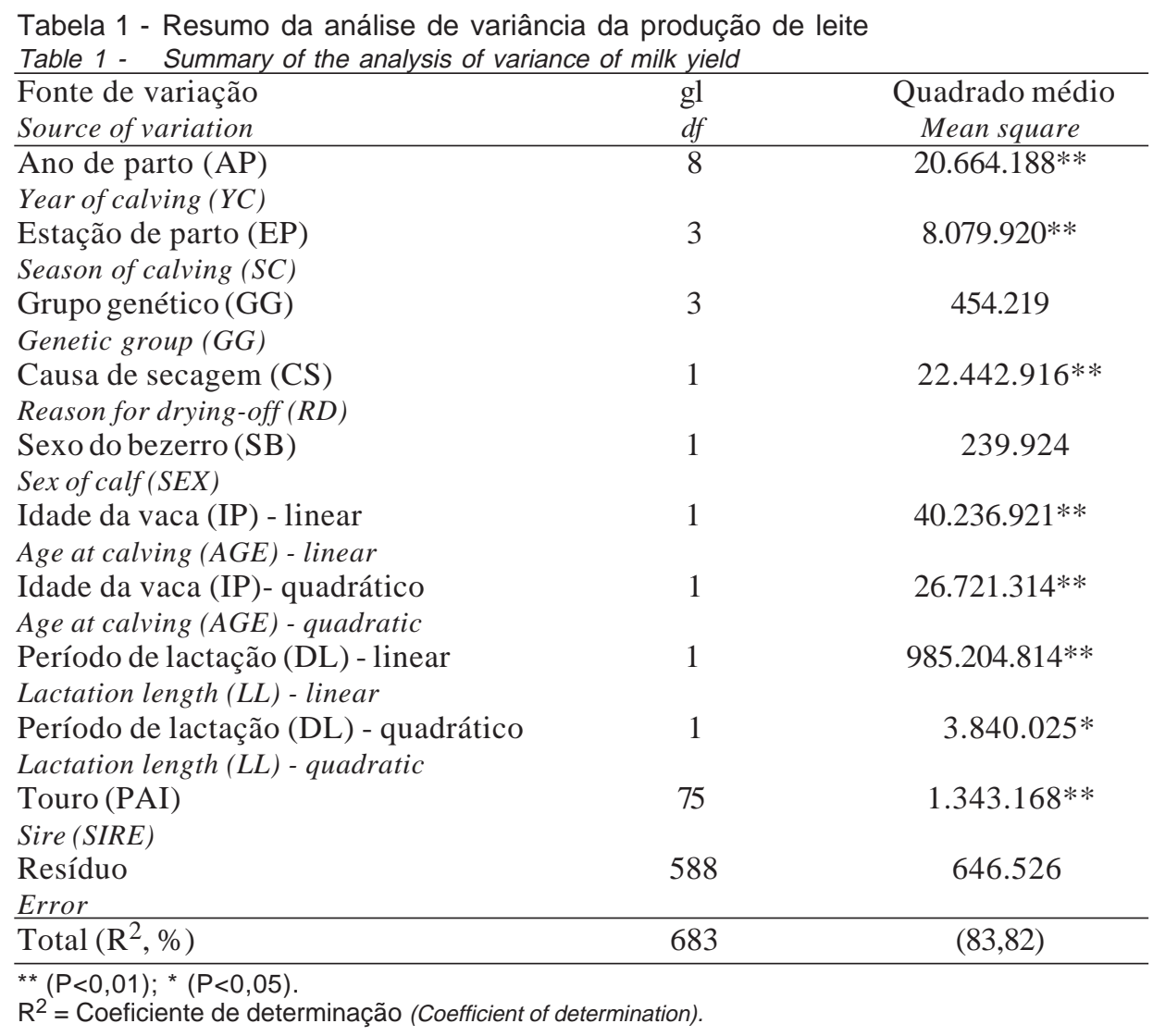


978 Rev. bras. zootec.

Tabela 2 - Número de observações $(\mathrm{N})$ e médias ( \pm erropadrão) da produção de leite (PL), de acordo com o ano de parto

Table 2 - Number of observations $(N)$ and least squares means ( \pm standard-error) of milk yield (MY), according to year of calving

\begin{tabular}{lcc}
\hline $\begin{array}{l}\text { Ano de parto } \\
\text { Year of calving }\end{array}$ & $\mathrm{N}$ & $\begin{array}{c}\mathrm{PL}, \mathrm{kg} \\
M Y\end{array}$ \\
\hline 1984 & 62 & $2944 \pm 155$ \\
1985 & 52 & $3694 \pm 147$ \\
1986 & 48 & $3995 \pm 146$ \\
1987 & 59 & $4503 \pm 127$ \\
1988 & 75 & $4974 \pm 112$ \\
1989 & 84 & $5221 \pm 106$ \\
1990 & 91 & $5300 \pm 100$ \\
1991 & 84 & $5478 \pm 104$ \\
1992 & 129 & $5988 \pm 102$ \\
\hline
\end{tabular}

As vacas com lactações iniciadas no verão (janeiro-março) foram menos produtivas que aquelas cujas lactações começaram nas outras estações do ano (Tabela 3). Este resultado é semelhante ao obtido por QUEIROZ et al. (1987) em um rebanho criado na região de São Carlos, SP. Na região Sudeste, os resultados obtidos até então têm mostrado que, em geral, as lactações iniciadas no outono (abril-junho) e inverno (julho-setembro) são mais produtivas que as iniciadas na primavera (outubro-dezembro) e no verão (janeiro-março), como relatado por NAUFEL (1965/66), COSTA et al. (1982), FREITAS et al. (1983), REIS e SILVA (1987) e CONCEIÇÃO JR. et al. (1993). Neste trabalho, o contraste linear entre as médias do verão e das demais estações do ano mostra diferença significativa de $470 \mathrm{~kg}$ de leite/ lactação $(\mathrm{P}<0,01)$, que pode ser atribuída à combinação dos efeitos de temperatura e umidade mais amenas durante o período de abril a setembro, em São Carlos, à melhor qualidade dos alimentos volumosos fornecidos às vacas em lactação durante aquele período do ano e, também, ao melhor ajuste da suplementação com concentrados, porque a qualidade e o consumo de volumosos eram conhecidos com maior precisão que na estação do verão.

A diferença entre as médias de produção de leite das lactações iniciadas no verão e nas demais estações do ano (470 kg/lactação) pode ser usada para estimar o número de vacas necessário para produzir na melhor época do ano e manter a cota de produção imposta pela indústria. Para cada dez vacas com início de lactação no verão (janeiro a março), seriam necessárias nove com lactações iniciadas nas demais estações do ano; portanto, como o estabelecimento da cota coincide com o inverno (julho a setembro) na região Sudeste, a porcentagem de vacas inseminadas na primavera (outubro a dezembro) e no verão (janeiro a março) pode ser $10 \%$ menor que nas demais estações do ano, mantendo-se a produção de leite constante ao longo do ano.

As médias estimadas de acordo com o grupo genético das vacas estão na Tabela 4 , não havendo diferenças significativas entre si. A maior diferença entre as médias, de $183 \mathrm{~kg}$, foi favorável às vacas puras por cruza de segunda geração controlada e puras de origem em relação às vacas cruzadas. Esta diferença não foi significativa, provavelmente devido à magnitude do erro experimental deste estudo.

Os resultados publicados sobre comparações entre grupos genéticos, em rebanhos com níveis altos de manejo (médias de produção de leite acima de $3000 \mathrm{~kg}$ por lactação), têm sido contraditórios. Na região Sudeste, ALVES NETO et al. (1967), QUEIROZ et al. (1987) e REIS e SILVA (1987), analisando dados provenientes de rebanhos com médias variando de 4200 a $4700 \mathrm{~kg}$ de leite por lactação, encontraram diferenças significativas entre grupos genéticos e favoráveis às vacas puras (PO e PC) em relação às cruzadas (até 15/16 Holandês). Entretanto, NEIVA et al. (1979), MADALENA et al. (1983), CONCEIÇÃO JR. et al. (1993) e BARBOSA et al. (1997), também analisando dados de rebanhos criados na região Sudeste, mas com médias de produção de leite variando de

Tabela 3 - Número de observações $(\mathrm{N})$ e médias ( \pm erropadrão) da produção de leite $(\mathrm{PL})$, de acordo com a estação de parto

Table 3 - Number of observations $(N)$ and least squares means ( \pm standard-error) of milk yield $(M Y)$, according to season of calving

\begin{tabular}{lcc}
\hline $\begin{array}{l}\text { Estação de parto } \\
\text { Season of calving }\end{array}$ & $\mathrm{N}$ & $\begin{array}{c}\mathrm{PL}, \mathrm{kg} \\
M Y\end{array}$ \\
\hline $\begin{array}{l}\text { Verão (janeiro-março) } \\
\text { Summer (January-March) }\end{array}$ & 188 & $4325 \pm 82^{\mathrm{b}}$ \\
$\begin{array}{l}\text { Outono (abril-junho) } \\
\text { Fall (April-June) }\end{array}$ & 166 & $4832 \pm 88^{\mathrm{a}}$ \\
$\begin{array}{l}\text { Inverno (julho-setembro) } \\
\text { Winter (July-September) }\end{array}$ & 158 & $4758 \pm 87^{\mathrm{a}}$ \\
$\begin{array}{l}\text { Primavera (outubro-dezembro) } \\
\text { Spring (October-December) }\end{array}$ & 172 & $4796 \pm 82^{\mathrm{a}}$ \\
$\begin{array}{l}\text { Médias, na coluna, seguidas de letras diferentes são diferentes } \\
\text { (P<0,01). }\end{array}$ & \\
$\begin{array}{l}\text { Means, within a column, followed by different letters are different }(P>01) . \\
\end{array}$
\end{tabular}


BARBOSA et al.

Tabela 4 - Número de observações $(\mathrm{N})$ e médias ( \pm erro-padrão) da produção de leite (PL), de acordo com o grupo genético

Table 4 - Number of observations $(N)$ and least squares means ( \pm standard-error) of milk yield (MY), according to genetic group

\begin{tabular}{|c|c|c|}
\hline Genetic group & & $M Y$ \\
\hline Cruzadas (de 5/8 até 15/16 Holandês) & 133 & $4586 \pm 114^{\mathrm{a}}$ \\
\hline $\begin{array}{l}\text { Crossbred (from 5/8 to } 15 / 16 \text { Holstein) } \\
\text { Puras por Cruza (>15/16 até } 31 / 32 \text { Holandês) }\end{array}$ & & \\
\hline $\begin{array}{l}\text { Puras por Cruza (>15/16 até } 31 / 32 \text { Holandês) } \\
\text { Upgraded cattle (>15/16 to 31/32 Holstein) }\end{array}$ & 217 & $4606 \pm 117^{\mathrm{a}}$ \\
\hline $\begin{array}{l}\text { Puras por Cruza (PC) de primeira geração controlada }(\mathrm{GC} 1) \\
\text { Graded cattle }(P C) \text { of first generation registered }(G C 1)\end{array}$ & 144 & $4749 \pm 110^{\mathrm{a}}$ \\
\hline $\begin{array}{l}\text { PC de segunda geração controlada }(\geq \mathrm{GC} 2)+\text { Puras de Origem }(\mathrm{PO}) \\
\text { Graded cattle of second generation registered }(\geq G C 2)+\text { purebred }(\mathrm{PO})\end{array}$ & 190 & $4769 \pm 86^{\mathrm{a}}$ \\
\hline
\end{tabular}

Médias, na coluna, seguidas de letras diferentes são diferentes $(P<0,01)$.

Means, within a column, followed by different letters are different $(P<.01)$.

3.000 (NEIVA et al., 1979) a $4000 \mathrm{~kg}$ por lactação (MADALENA et al., 1983), não encontraram diferenças significativas entre os grupos genéticos estudados.

O resultado obtido neste trabalho mostra que não houve efeito significativo de grupo genético, quando a média de produção de leite foi mais alta $(4.957 \mathrm{~kg})$ que a amplitude encontrada para a região Sudeste, com efeito significativo de grupo genético (ALVES NETO et al., 1967; QUEIROZ et al., 1987; e REIS e SILVA, 1987). Estes resultados levam à suposição de que poderia ocorrer interação entre grupo genético e nível de produção, mas esta hipótese não pode ser testada neste trabalho. Nos rebanhos com nível de manejo mais alto, a produção de leite das vacas cruzadas seria limitada pelo seu potencial genético mais baixo, e não pelas condições de ambiente, enquanto, nos rebanhos com nível de manejo mais baixo, as vacas puras de origem e puras por cruza não expressariam todo o potencial genético para produção de leite, porque as condições de ambiente e manejo seriam limitantes. No caso deste trabalho, visto que o rebanho se encontra em evolução, quanto à produção de leite e ao número de vacas em lactação por ano (Tabela 2), e não houve interação entre grupo genético e estação de parto (Tabela 1), pode-se inferir que as práticas de manejo ainda não atingiram níveis suficientemente altos para que as diferenças entre os grupos genéticos se manifestassem totalmente (Tabela 4) ou, ainda, que não há diferenças significativas entre os grupos genéticos, quanto aos valores genotípicos para produção de leite, mesmo que para efeito de análise dos dados as vacas tenham sido classificadas de acordo com a sua qualificação no sistema de registro genealógico da Associação Brasileira de Criadores de Bovinos da Raça Holan- desa. O mais provável é que a combinação desses fatores seja a causa.

MADALENA et al. (1983) concluíram que, na região Sudeste, há possibilidade de se utilizar gado Holandês nos sistemas de produção de leite com menores limitações de manejo e, também, que o gado mestiço Holandês x Zebu pode ser utilizado em fazendas com níveis de produção relativamente altos (4200 kg/lactação). Embora o número de observações seja pequeno, o resultado deste trabalho sugere que a média de produção de leite por lactação pode ser maior que aquela obtida por NEIVA et al. (1979), MADALENA et al. (1983), CONCEIÇÃO JR. et al. (1993) e BARBOSA et al. (1997), os quais não encontraram diferenças significativas entre grupos genéticos e, mesmo assim, as diferenças não foram tão grandes quanto à produção de leite (Tabela 4).

O sexo do bezerro não influenciou a produção de leite, concordando com a maioria dos resultados relatados na literatura brasileira sobre o assunto (FREITAS et al., 1983; BARBOSA et al., 1997). No Brasil, apenas SIQUEIRA (1979) verificou que as lactações seguintes ao nascimento de machos foram mais produtivas.

As vacas com lactações encerradas por motivo de pré-parto foram mais produtivas que aquelas cujas lactações foram terminadas por baixa produção ou outras causas (Tabela 5). A causa de secagem foi relatada como um dos fatores mais importantes que influenciam a produção de leite em um rebanho da raça Holandesa criado na região da Mantiqueira Paulista (BARBOSA et al., 1997). Visto que as vacas com lactações encerradas por motivo de secagem pré-parto permanecem em lactação por um período mais curto, porque também apresentam períodos 
980 Rev. bras. zootec.

Tabela 5 - Número de observações $(\mathrm{N})$ e médias $( \pm$ erropadrão) da produção de leite (PL), de acordo com a causa de secagem

Table 5 - Number of observations $(N)$ and least squares means ( \pm standard-error) of milk yield (MY), according to drying-off reason

\begin{tabular}{lcc}
\hline $\begin{array}{l}\text { Causa de secagem } \\
\text { Drying-off reason }\end{array}$ & $\mathrm{N}$ & $\begin{array}{c}\text { PL }(\mathrm{kg}) \\
M Y\end{array}$ \\
\hline $\begin{array}{l}\text { Pré-parto } \\
\begin{array}{l}\text { Pre-calving } \\
\text { Baixa produção/outras causas }\end{array}\end{array}$ & 251 & $4903 \pm 78^{\mathrm{a}}$ \\
$\begin{array}{l}\text { Low production/other reasons } \\
\text { Médias, na coluna, seguidas de letras diferentes são diferentes } \\
(\mathrm{P}<0,01) .\end{array}$ & $4452 \pm 61^{\mathrm{b}}$ \\
$\begin{array}{l}\text { Means, within a column, followed by different letters are different }(P<.01) .\end{array}$
\end{tabular}

de serviço mais curtos que aquelas com lactações terminadas por baixa produção, o resultado obtido indica que a adoção de práticas mais adequadas de manejo reprodutivo e da lactação é recomendada para obter os benefícios decorrentes das diferenças na causa de secagem. Uma dessas práticas seria a inseminação das vacas no primeiro estro pós-parto, ao contrário da recomendação generalizada de se inseminar somente após 60 dias pós-parto, visando à redução do período de serviço.

A idade da vaca ao parto teve efeitos linear e quadrático sobre a produção de leite na lactação, concordando com os resultados relatados na literatura brasileira (COSTA et al., 1982; FREITAS et al., 1983). As estimativas dos coeficientes de regressão linear e quadrática foram iguais a $18,86 \pm 2,39 \mathrm{~kg} / \mathrm{mês}$ e $-0,2934 \pm 0,0456 \mathrm{~kg} / \mathrm{mês} 2$ de aumento na idade da vaca ao parto, respectivamente. A estimativa do coeficiente de regressão linear foi menor que o valor obtido por COSTA et al. (1982), de 45,46 kg/mês. A produção máxima de leite $(5526 \mathrm{~kg})$ foi obtida aos 87 meses de idade, o que corresponde à quinta lactação, quando se consideram as médias observadas no rebanho da idade ao primeiro parto de 32,1 meses e do intervalo de partos de 13,8 meses. A partir da quinta lactação, a curva de produção de leite decresce de acordo com a idade da vaca, mas de forma suave, pois os coeficientes de regressão foram de baixa magnitude. O descarte da vaca pode ser feito após a sétima lactação, que corresponde à idade aproximada de 124 meses, desde que a vaca mantenha intervalos de partos regulares de 14 meses ou menos. Na raça Holandesa, resultado semelhante foi relatado por COSTA et al. (1982).
A duração do período de lactação teve efeitos linear e quadrático sobre a produção de leite, com estimativa de coeficientes de regressão de 15,83 $\pm 0,41$ $\mathrm{kg} / \mathrm{dia}$ e $-0,0057 \pm 0,0023 \mathrm{~kg} / \mathrm{dia}^{2}$. Os resultados publicados até então relataram efeito linear da duração do período de lactação na produção de leite (NEIVA et al., 1979; FREITAS et al., 1983). As estimativas dos coeficientes de regressão obtidas neste trabalho mostram que houve acréscimo de $15,83 \mathrm{~kg}$ de leite por dia de aumento, na duração da lactação acima da média de 305,5 dias, e decréscimo de $0,0057 \mathrm{~kg}$ de leite por dia de aumento ao quadrado naquela duração.

O efeito de touro foi significativo (Tabela 1), indicando que há variação genética para obtenção de resposta à seleção para produção de leite no rebanho estudado. Este resultado está de acordo com a maioria dos trabalhos relatados na literatura brasileira sobre o assunto (COSTA et al., 1982; FREITAS et al., 1983; QUEIROZ et al., 1987; e BARBOSA et al., 1997) e indica que a correta escolha dos touros a serem utilizados, entre os disponíveis nas centrais de inseminação artificial, pode resultar em diferenças na produção de leite do rebanho.

\section{Conclusões}

A duração do período de lactação foi o fator mais importante na variação da produção de leite, seguida do ano de parto, da causa de secagem, de touro e da estação de parto.

Houve melhoramento no desempenho do rebanho, de acordo com os anos de parto, indicando que as práticas de manejo sofreram mudanças favoráveis ao longo do período, principalmente quanto à alimentação na época da seca, com reflexos positivos na produção de leite do modelo físico de sistema de produção da Embrapa Pecuária Sudeste, São Carlos, SP.

As lactações encerradas por motivo de secagem pré-parto foram mais produtivas que as encerradas por baixa produção, indicando que as vacas podem ser inseminadas no primeiro estro, mesmo que este ocorra antes de 60 dias pós-parto.

A produção de leite do rebanho pode ser mantida constante durante o ano, inseminando-se $10 \%$ a mais de vacas nas estações mais favoráveis (outono e inverno).

Na região Sudeste, é possível a utilização de vacas cruzadas (de 5/8 até 15/16 Holandês) e a obtenção de níveis de produção de leite relativamente altos (4500 kg por lactação). 


\section{Referências Bibliográficas}

ASSOCIAÇÃO BRASILEIRA DOS CRIADORES DE BOVINOS DA RAÇA HOLANDESA - ABCBRH. 1986. Regimento do Serviço de Controle Leiteiro. São Paulo. 8p.

ALVES NETO, F., FANG, I., TELLES, J. D. M. et al. 1967. Comportamento médio das vacas e rebanhos controlados pelo Serviço de Controle Leiteiro da Associação Paulista de Criadores de Bovinos, 1945-1966. Rev. Criadores, 38:18-108.

BARBOSA, P.F., VILLELA, C.L., LEITE NETO, M. C. Produção de leite e duração da lactação em um rebanho da raça Holandesa na região da Mantiqueira Paulista. In: REUNIÃO ANUAL DA SOCIEDADE BRASILEIRA DE ZOOTECNIA, 34, 1997, Juiz de Fora, MG. Anais... Juiz de Fora: SBZ, v.3, p.97-99, 1997.

CÂMARA SETORIAL DE LEITE. 1991. Custo da produção de leite. Brasília: SNPA, EMBRAPA/CNPGL/UEPAE/ ABPLB. 79p.

CONCEIÇÃO JR., V., SILVA, H.M., PEREIRA, C.S. 1993. Fatores ambiente e genéticos que afetam a produção de leite e de gordura em vacas da raça Holandesa. Arq. Bras. Med. Vet. Zootec., 45(1):81-88.

COSTA, C.N., MILAGRES, J.C., SILVA, M.A. et al. 1982. Fatores genéticos e de meio na produção de leite de um rebanho Holandês no Estado de Minas Gerais. R. Soc. Bras. Zootec., 11(1):70-85.

FREITAS, M.A.R., DUARTE, F.A.M., LÔBO, R.B. 1983. Fatores não genéticos de variação na produção de leite de vacas da raça Holandesa. Arq. Bras. Med. Vet. Zootec., 35(4):575-590.

MADALENA, F.E., VALENTE, J.,TEODORO, R.L. et al. 1983. Produção de leite e intervalo entre partos de vacas HPB e mestiças HPB: Gir num alto nível de manejo. Pesq. Agropec. Bras., 18(2):195-200.

NAUFEL, F. 1965/66. Efeitos de alguns fatores ambientais e genéticos na produção de leite e de gordura do rebanho experimental Holandês Preto e Branco do Departamento de Produção Animal de São Paulo. Bol. Ind. Anim., 23(único):21-54.

NEIVA, R.S., SILVA, H.M., SAMPAIO, I.B.M. 1979. Alguns fatores de meio influenciando a produção de leite, em um rebanho Holandês, no sul do Estado de Minas Gerais. Arq. Bras. Med. Vet. Zootec., 31(2):263-273.

QUEIROZ, S.A., GIANNONI, M.A., RAMOS, A.A. et al. 1987. Environmental effects on the variation of productive traits in Holstein-Friesian $\mathrm{x}$ Zebu crossbred cattle in the region of São Carlos, State of São Paulo. I. Milk yield. Rev. Bras. Genet., 10(1):63-73.

REIS, R.B., SILVA, H.M. 1987. Influência de alguns fatores de meio sobre as principais características produtivas em rebanhos holandeses. I. Produção de leite, produção de gordura, percentagem de gordura. Arq. Bras. Med. Vet. Zootec., 39(2):273-290.

SIQUEIRA, A.C.M.F. Fatores de variação da produção de leite e gordura de vacas da raça Holandesa, variedade Malhada de Preto. São Paulo: USP, 1979. 118p. Tese (Doutorado) Instituto de Biociências/Universidade de São Paulo, 1979.

STATISTICAL ANALYSIS SYSTEMS INSTITUTE - SAS. 1993. Statistical Analysis Systems User's Guide: Stat, Version 6, 4 ed., v. 1/2. Cary, NC: SAS Institute.

Recebido em: 12/02/98

Aceito em: 14/05/99 